\title{
Analysis on the innovation and impact of BIM technology in the field of engineering cost
}

\author{
Wei Feng \\ Beijing Institute of Economic and Management,Beijing,102602 China
}

\begin{abstract}
Recently, more and more attention has been paid to the application of BIM (building information model) technology in the engineering field. Most well-known domestic and Design Institute to establish a BIM team. Meanwhile, many large-scale projects also incorporate BIM technology for construction and management, This technology is the construction industry led to a major change. The impact of BIM technology on the cost consulting industry in China is still in the embryonic stage. But with the continuous improvement and development of BIM Technology, it will gradually be involved in the whole life cycle of the project. Including the design, budget, construction and post evaluation stage, This article will be focused on the impact of BIM technology innovation and engineering cost fields were discussed and analyzed.
\end{abstract}

Key Words-BIM technology engineering cost innovation attack

\section{INTRODUCTION}

Construction project management is mainly composed of cost management, schedule management and quality management of the three major projects, $\mathrm{n}$ the process of project management, data transmission fault phenomenon is very common, to solve this problem is a hot topic in the current construction management. BIM Technology universal building information modeling technology is throughout the whole process of the project of digital model application technology, for the project cost management can be effective sharing of information resources, in the different stages of the project completed transfer information, support project decision and departments coordinated operations, for the construction management is designated in the era of innovation. Here we will begin BIM technology, explore its innovation in the field of project cost and impact.

Currently, BIM technology has been recognized by the international community as a revolutionary technology for the development of construction industry, its comprehensive application, the construction industry will have an immeasurable impact on the progress of science and technology. BIM Technology with a new 3D model as a carrier of the information project, change the project cost management system, through visual means to achieve cost management of real time and dynamic adjustment, more efficient, accurate and rapid access to all kinds of cost information, improve management level of the project construction cost, implementation of construction project cycle of information management, enhance the overall efficiency of the industry, has a high application value.

2. The development background and current situation of BIM Technology

BIM (building information modeling) is referred to as the "building information modeling, initially originated in the 1970 s in the United 
States, by the United States of Georgia and university buildings and Computer College (Georgia Tech College ofArchitecture and Computing) chuck Eastman Dr. chuck Eastman, $\mathrm{Ph} . \mathrm{D}$.) is proposed. So, BIM was first developed from the United States together with the process of globalization, has been extended to Europe, Japan, Korea, Singapore and other countries, currently, BIM development and application of these countries have reached a certain level. In China, the concept of BIM was first introduced by the Autodesk Inc in 2002 by the Chinese market. After nearly 14 years of time, China's construction industry is experiencing a BIM baptism. Software companies, design units, real estate developers, construction units, universities and research institutions have begun to set up BIM research institutions. National " Eleventh Five-Year" plan BIM has become the key project of national science and technology support program, the national "Twelfth Five Year Plan" to further BIM building information model as a key research topic of information technology. At present, there are many domestic construction projects in various stages of the project to use the BIM technology. Among them, the Shanghai World Trade Center building is a typical case of the whole life cycle of application of BIM, the entire project implementation process by the owners, the use of BIM technology for the design, construction, operation of a full range of planning. However, throughout China and the global construction industry, the application of BIM technology is mostly in the form of project management in the design stage and the construction stage, for its application in the project cost but few people explore.

\section{Current situation of engineering cost management in China}

BIM technology is leading the construction industry to a higher level of development, at this stage there are still some problems in the engineering cost management, we will be effective through the application of BIM technology to solve.

The cost is difficult to realize the whole process management

Most of the project cost management in our country is lack of the management mode of the system, and the lack of comprehensive management awareness of the whole process of construction project. Construction units, design units, construction units, supervision units lack unified cost target and communicate with each other coordination mechanisms, resulting in their own interests as the starting point of communication and coordination phenomenon, the main reason is not for the project itself formed multi identity of collaboration platform.

Cost analysis of the fineness of the data is not enough, the function is weak, data accumulation is difficult

A project cost process is generally divided into three stages of budget preparation, budget preparation, settlement preparation. Personnel in each stage one of the stages of the project itself requirements are different, the formation of three stage is the preparation of the data is relatively isolated are different only in the comparison of the cost to be controlled, and cost data no based on the project itself formation effective data association. In this way, the cost of the various stages of the work of the preparation of higher work, take up more time, more labor, resulting in a large number of human and material resources consumption and waste.

\section{Data sharing collaboration and accumulation difficulties}

Why the previous project has so many risks, because the data is fragmented, forming an information island, the information can not be 
integrated and shared, resulting in the disorderly flow of information. Construction industry is almost a fragmented industry structure, the key is the lack of a common platform for interaction, resulting in the loss of information, information transmission errors, etc.. Because of the engineering construction design to a lot of units, the unit cost division of the data is difficult to share, resulting in low efficiency of business cooperation, a waste of a lot of manpower and material resources. And there is no system of database, data accumulation is just in the brain of professionals, senior professionals have no way to get the data to share other personnel inside the enterprise.

\section{Effect of BIN technology on engineering cost}

The development of BIM technology has played a great role in the field of engineering cost, and greatly improve the efficiency of engineering cost, and create a good condition for the development of the information system.

The innovation of engineering cost by BIM

\section{Technology}

BIM is based on the construction project of the relevant information data as the basis of the model, the establishment of the building model, through digital information simulation of the building with the real information. It has five major characteristics of visualization, coordination, simulation, optimization and can be out of the picture. Basic BIM usage America AEC field investigation and study on the summary of the current application of BIM model construction management platform include: on-site integration, optimization, scheduling, project the amount of statistics, safety management, quality management, cost management, digitization construction Wait. BIM is a new technology, which is applied to the whole process from design to construction to operation management, and it runs through the whole life cycle of the project. The whole process of the project construction phases can be all-round, multi angle, different levels of processing of BIM system according to the requirements of different specification, prior to the various problems early warning, construction projects in various participants to in view of the problems that may arise in advance to make the correct response, avoid loss and other serious consequences, and provides a solid foundation for collaborative work.

The current construction project cost management has entered the stage of the whole process control, cost control and risk control pressure, the traditional cost management has been unable to meet demand, from short-term practical, cost management plan to the whole process of the development of fine management has become the only way. Closely related to the call of construction project cost management of the whole process control and mass engineering based data, the timeliness and accuracy of data applications need to continuously improve the engineering data base of automation, information and intelligent process, thus in the whole process of control provide support will all kinds of information policy based, saving process control time cost and the economic cost, efficient supervision and engineering, to realize real-time verification contrast. BIM technology has been widely used in the engineering field worldwide scope, and application of practice with the continuous development of the upgrade, is China's "Twelfth Five-Year Plan" key projects. BIM technology key lies in the use of computer technology to build three-dimensional model database, adjusted for changes in construction project management in real-time, accurate to call various related data, to improve the quality of 
decisions, accelerate decision-making, thereby reducing the project cost control, guarantee project quality, to enhance benefits. The emergence and application of BIM technology promotes the software engineering development, especially in the project cost management system, from a two-dimensional and static is developing toward the direction of $3 \mathrm{D}$ and dynamic, prompting the construction whole process cost management appear constantly new breakthrough, with higher precision and higher effects rate of quantities calculation. The application of BIM technology in engineering management has experienced from lower level to higher level.

\section{The impact of BIM technology on} engineering cost

BIM brought two major changes in the field of cost, BIM compared with traditional models, has the following two salient points: model integrated the construction of the entire life cycle of the stage, the professional information; the second is model as a platform to support multi professional and collaboration. Thus, it will bring to the construction engineering cost industry thinking and work on the revolutionary transformation. Below, we will traditional cost activities and BIM trend of construction project life cycle stages involved in construction activities, on the cost and the work in the way of thinking, a simple comparison, intended to highlight the changing needs and necessity. Digital cost thinking into the thinking method of cost model; generally speaking, current engineering cost mode will experience process is as follows: Project in the feasibility study stage, some of the larger enterprises from the historical accumulation of the index in the library screened with existing projects similar to the historical data and the feasibility study report project estimation; design stage with preliminary construction drawing a design budgetary estimate; to bidding and tendering stage, uses the detailed construction CAD drawings into software, respectively, the calculation amount and valuation, then get the construction drawing budget; to occurred in the construction stage of the recording process change, bid ask spread and claim and get the cost of clearing and settlement by adjustment of the budget. And through the BIM model. It is easy to check out which projects do not have the actual cost data, supervise the cost line real-time inventory, provide the actual data, pooled analysis capability has been greatly enhanced, the speed, short cycle cost analysis is no longer difficult, the workload is small, high efficiency.

\section{Advantages of BIM technology in the field of engineering cost \\ Accurate calculation of engineering} quantity

After the introduction of BIM Technology and base cost personnel only according to the local engineering quantity calculation rules, in BIM software corresponding adjustment buckle reduction calculation rules, system will automatically complete the component deduction arithmetic, more precise, fast statistics project information. Based on BIM automatic calculation method of cost professionals from the tedious work of the liberation, greatly improve the work efficiency, at the same time can make the project quantity calculation to get rid of human error factors. Resource management plan: use of BIM 3D model, join the dimensions of time, cost formation of SD architecture model, to realize the dynamic real-time monitoring can more reasonably arrange capital plans, planning, material planning and plan of mechanical. Through the SD model to that the workload in any time period of each project, and to the time period of the cost accounting, can be more accurate to make school industry and trade and 
financial plan, which is the premise condition for the implementation of the fine cost management.

\section{Reasonable design change and claim management}

The introduction of BIM technology, you can directly relate to the content of the design changes to the model. When the change occurs, only the model a little adjustment, the software will automatically summarize the changes in the amount of the relevant works, fast and accurate. In the 5D model, even the change of cost can be brought out directly, so that designers can make a clear understanding of the influence of the change of design scheme on the cost. In contrast: the traditional emphasis on both the price (contract price, settlement price), the BIM technology will be completely subversive. In a BIM model, each component is endowed with parametric information, such as progress, material, position, working time consumption and procedure arrangement, we can any combination of information of each component, for project compared to provide strong technical support.

BIM technology applied in the whole process of cost management, not just a simple application of the concept or technology. More importantly, based on the BIM technology, BLM completely break the construction project cost management of horizontal and vertical information sharing and collaborative barriers, and promote the project cost management into the real time, dynamic, accurate analysis of the times. BIM application to improve the engineering project of the participating parties to cost control capacity, but also for the parties to save costs. BIM technology and the Internet, effectively improve the transparency of the construction market, is conducive to the standardization of the construction industry in our country, and effectively avoid the bidding and procurement process of corruption. At the same time, accelerate the construction industry from extensive to intensive change, is conducive to improve the efficiency of the construction industry, accelerate the construction industry concentration. It is conducive to the implementation of fine management, reduce waste, is conducive to low carbon construction, in line with China's economic development trend.

\section{Conclusion}

In short, the whole life cycle cost management based on BIM technology in favor of the construction of sustainable development, in line with China's basic national conditions and requirements for the construction industry, it is a major popular model of the future cost management. The construction project management information requirements established cost management information system for the whole life cycle as soon as possible, in order to support the smooth progress of construction cost management. BIM as a basis for full life-cycle cost management is the core of information systems, to leverage the power of BIM to meet the different needs of users personalized features, to establish the connection each stage longitudinal horizontal integration of the participating parties, to achieve the integration of systems and software information Systems is a full life-cycle cost management in today's imperative. At present the cost of software development has been relatively mature, the most important of the three valuation software Glodon, Luban and Tsinghua Brownsville, are beginning to BIM for research in the future will certainly be more binding BIM technology, which is more suitable for the whole process of this project cost management, to achieve transparent data sharing, coordination projects, information technology function. 


\section{Reference}

[1] He Guanpei, BIM in the location of the construction industry, the evaluation system and the possible application of $[\mathrm{J}]$, civil engineering and construction information technology, 2010 (3):56-58

[2] Ernstrom B ,Hanson D. The constructors guide to BIM[M].New York,AGC of America, 2015:42-45

[3] Yang Baoming, Engineering cost management innovative thinking $[\mathrm{N}]$, construction times, 2013-12-20(6)

[4] Cui Haodong, On the project cost management in the use of $[\mathrm{J}]$ BIM, construction engineering technology and design. 2015(6):78-81 